\title{
Microwave Assisted Synthesis of Zinc Oxide Nanoparticles and Its Antimicrobial Efficiency
}

\author{
R. Deepa ${ }^{1}$, D. Muthuraj ${ }^{1, *}$, E. Kumar ${ }^{2}$, V. Veeraputhiran ${ }^{3}$ \\ ${ }^{1} P G$ and Research Department of Physics, The M.D.T. Hindu College, Tirunelveli - 627 010, Tamilnadu, India. \\ ${ }^{2}$ Department of Physics, School of Science, Tamil Nadu Open University, Chennai - 600 015, Tamilnadu, India. \\ ${ }^{3} R \&$ D Department, Alba Industries Pvt. Ltd., Thoothukudi - 628 103, Tamilnadu, India.
}

\section{ART ICLE DETAILS}

\section{Article history:}

Received 05 March 2019

Accepted 27 March 2019

Available online 31 March 2019

\section{Keywords:}

Zinc Oxide

Microwave Method

Antimicrobial Activity

\begin{abstract}
A B S T R A C T
Zinc oxide $(\mathrm{ZnO})$ nanoparticles have been synthesized via microwave-assisted method. The structural analysis was carried out using X-ray diffractometer. It showed that the $\mathrm{ZnO}$ nanoparticle exhibited hexagonal structure. Further the $\mathrm{ZnO}$ product was investigated by FT-IR and SEM analysis. Also antimicrobial efficiency in different concentrations have been studied and found good activity against Escherichia coli.
\end{abstract}

\section{Introduction}

Zinc oxide, $\mathrm{ZnO}$ is inorganic compounds also known as zinc cites and occurs rarely in nature, generally in a crystalline form. It is usually orange or red in color due to presence of manganese impurity. It usually appears as a white crystalline powder, which is nearly insoluble in water. Most of $\mathrm{ZnO}$ which is used commercially is produced synthetically. $\mathrm{ZnO}$ is actually a wide-bandgap semiconductor of the II-VI semiconductor group. $\mathrm{ZnO}$ is considered a good candidate for transparent conducting electrodes in solar cells because it is transparent to the visible light [1]. It can occur in one dimensional (1D), two dimensional (2D) and three dimensional (3D) structures. One dimensional structure makes up the largest group including needles, helixes, nanorods, ribbons, belts, wires and combs. Zinc oxide can occur in two dimensional structures such as nanopellets, nanosheet/nanoplate [2]. This has several favorable properties like high electron mobility, good transparency, wide bandgap for semiconductivity, high room-temperature luminescence, etc. These properties are used in applications for electrodes in liquid crystal displays as well as in energy-saving and heat-protecting windows [3]. Zinc oxide ( $\mathrm{ZnO}$ ) has a stable wurtzite structure with lattice spacing a $=0.325$ nanometers and $c$ $=0.521$ nanometers. It is a prime candidate for UV and blue LED and lasers due to its large exciton binding energy of $60 \mathrm{MeV}[4,5]$. These materials have found to use as a transparent conducting oxide [6,7]. This present work has employed to synthesis such $\mathrm{ZnO}$ nanoparticles via simple and efficient technique.

\section{Experimental Methods \\ 2.1 Materials}

All the chemicals were used as analytical grade without any further purification. Zinc nitrate hexahydrate and sodium hydroxide were used to prepare the nanoparticles of this work. Double distilled deionized water used in this investigation. Disc diffusion method has employed with Escherichia coli and Staphylococcus aureus.

\subsection{Synthesis}

Zinc nitrate hexahydrate $\left(\mathrm{ZnNO}_{3} .6 \mathrm{H}_{2} \mathrm{O}\right)$ and sodium hydroxide $(\mathrm{NaOH})$ were taken in 1:4 molar ratio and dissolved completely in de-ionized water separately. Then the dissolved $\mathrm{ZnNO}_{3} \cdot 6 \mathrm{H}_{2} \mathrm{O}$ was added with ethylene glycol. Further, $\mathrm{NaOH}$ solution was added drop wise into the above mixture under vigorous stirring. Then the prepared mixture solution was kept in the microwave oven ( $900 \mathrm{~W}, 2450 \mathrm{MHz}$ ) for about 30 minutes. Finally, the as-prepared sample was centrifuged several times in double distilled water, ethanol and dried at $150{ }^{\circ} \mathrm{C}$ for 24 hours, resulting in the formation of $\mathrm{ZnO}$ nanoparticles.

\subsection{Instrumentation}

Powder X-ray diffraction pattern of the nanoparticles was obtained using a Rigaku Ultima IV powder X-ray diffractometer. The sample was scanned over the required range for $2 \theta$ values. The FTIR spectrum of the sample was recorded within the wavenumbers from $4000 \mathrm{~cm}^{-1}$ to $400 \mathrm{~cm}$. ${ }^{1}$ by using Perkin Elmer Frontier FTIR. The antimicrobial activity was determined by disc diffusion method.

\section{Results and Discussion}

\subsection{X-Ray Diffraction Method}

The XRD pattern of pure ZnO nanoparticles is shown in Fig. 1. The XRD result shows that the sharp diffraction peaks formed at $33^{\circ}$ and $58.7^{\circ}$ confirms the formation of $\mathrm{ZnO}$ nanoparticles and the well-defined peaks indicate the good crystallinity of synthesized material. The peaks formed at $33^{\circ}$ and $58.7^{\circ} \mathrm{can}$ be indexed to $(002)$ and $\left(\begin{array}{lll}1 & 1 & 0\end{array}\right)$ planes of $\mathrm{ZnO}$ crystal which matches well with the JCPDS card No. 80-0075 and the structure of the $\mathrm{ZnO}$ nanoparticles was found to be hexagonal crystal. The crystalline size of $\mathrm{ZnO}$ nanoparticles was calculated using the value of FWHM from the most intense XRD peaks as around $45 \mathrm{~nm}$ by using Scherrer formula [8],

$$
\mathrm{D}=\frac{K \lambda}{\beta \cos \theta}
$$

where $D$ is the crystallite size, $K$ is the shape factor $(0.94), \lambda$ is the wavelength of X-rays $(\lambda=1.54059 \AA), \beta$ is the full width at half maximum (FWHM) of the diffraction peaks and $\theta$ is the angle of diffraction.

The lattice parameters ' $a$ ' and ' $c$ ' for the hexagonal structure can be calculated by using equation,

$$
\frac{1}{d^{2}}=\frac{4}{3}\left[\frac{h^{2}+k^{2}+h k}{a^{2}}\right]+\frac{l^{2}}{c^{2}}
$$


The calculated values of the lattice parameters are $\mathrm{a}=3.1217 \AA$ and $\mathrm{c}=$ $5.2962 \AA$. The values of ' $a$ ' and ' $c$ ' are in agreement with the standard values of $\mathrm{ZnO}$ single crystal $(\mathrm{a}=3.250 \AA \AA$ and $\mathrm{c}=5.207 \AA)$.

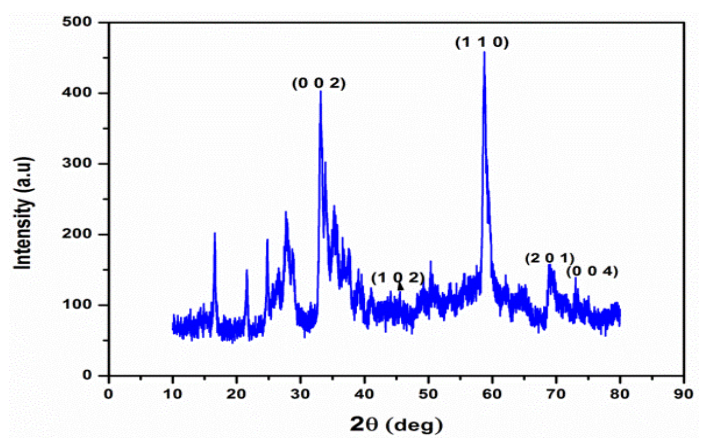

Fig. 1 XRD pattern ZnO nanoparticles

\subsection{FT-IR Method}

The FT-IR spectra of ZnO nanoparticles synthesized by microwave assisted hydrothermal method as shown in Fig. 2. The peak at low wave number region of $576 \mathrm{~cm}^{-1}$ is assigned to $\mathrm{ZnO}$ group $[9,10]$. The sharp peak at $1123 \mathrm{~cm}^{-1}$ is due to $\mathrm{C}-\mathrm{H}$ plane bending vibration [11]. The band appears at $1619 \mathrm{~cm}^{-1}$ may be attributed to $\mathrm{C}=\mathrm{C}$ stretching mode ring [12]. These $\mathrm{C}-\mathrm{H}$ and $\mathrm{C}=\mathrm{C}$ vibrations are due to the capping agent ethylene glycol. The peak at $3278 \mathrm{~cm}^{-1}$ is due to the absorption of water during the preparation of IR pellet [13].

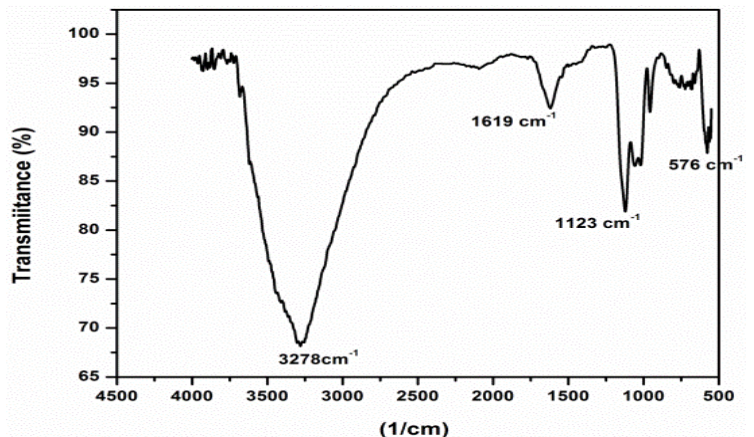

Fig. 2 FT-IR spectrum of $\mathrm{ZnO}$ nanoparticles

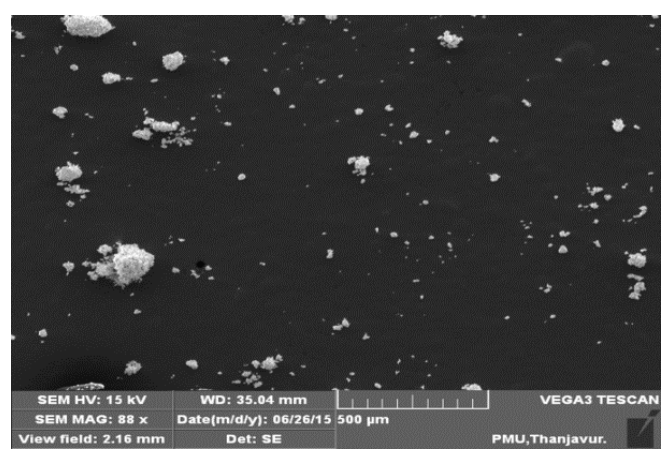

Fig. 3 SEM image of ZnO nanoparticles

\subsection{SEM Analysis}

The SEM micrograph of the pure $\mathrm{ZnO}$ nanoparticles synthesized by microwave assisted hydrothermal method as shown in Fig. 3. It can be observed that nanosized $\mathrm{ZnO}$ particles are formed as nanoclusters. Also, all the particles were eventually distributed in the surface. In addition to that from Fig. 3 the agglomeration of crystalline nano $\mathrm{ZnO}$ particles are clearly visible while observing these macro particles in the image.

\subsection{Antimicrobial Activity}

The antibacterial activity of pure $\mathrm{ZnO}$ in different concentrations against bacteria Escherichia coli and Staphylococcus aureus were studied. The antibacterial activity was determined based on an inhibition zone. No zone of inhibition was observed for the negative control. Escherichia coli positive control, for which the zone of inhibition ranges from 13 to $29 \mathrm{~mm}$. The highest mean zone of inhibition $(22 \mathrm{~mm})$ is recorded for pure $\mathrm{ZnO}$. Against Escherichi coli, which clearly indicates the mechanism of the biocidal action of the $\mathrm{ZnO}$ that destroys the outer of the bacteria leads to the death. The observed difference in the diameter of the inhibition zone may be due to the difference in the susceptibility of the different bacteria to the prepared $\mathrm{ZnO}$ particles.

\section{Conclusion}

The XRD result shows that the sharp diffraction peaks formed at $33^{\circ}$ and $58.7^{\circ}$ confirms the formation of $\mathrm{ZnO}$ nanoparticles and the welldefined peaks indicate the good crystallinity of synthesized material. The peaks formed at $33^{\circ}$ and $58.7^{\circ}$ can be indexed to $\left(\begin{array}{lll}0 & 0 & 2\end{array}\right)$ and $\left(\begin{array}{lll}1 & 1 & 0\end{array}\right)$ planes of $\mathrm{ZnO}$ crystal which matches well with the JCPDS card No. 80-0075 and the structure of the $\mathrm{ZnO}$ nanoparticles was found to be hexagonal crystal. The crystalline size of $\mathrm{ZnO}$ nanoparticles was calculated using the value of FWHM from the most intense XRD peaks as around $45 \mathrm{~nm}$ by using Scherrer formula. The FT-IR spectra of ZnO nanoparticles synthesized by microwave assisted hydrothermal method. The peak at low wave number region of $576 \mathrm{~cm}^{-1}$ is assigned to $\mathrm{ZnO}$ group. The peak at $3278 \mathrm{~cm}^{-1}$ is due to the absorption of water during the preparation of IR pellet. The SEM micrograph of synthesized $\mathrm{ZnO}$ nanoparticles clearly depicts the crystalline structures. The antibacterial activity of nano ZnO in different concentrations against bacteria Escherichia coli and Staphylococcus aureus have studied and found that synthesized nanoparticles of $\mathrm{ZnO}$ shows good antibacterial activity against Escherichia coli bacterium.

\section{References}

[1] D.R. Lide, Hand book of chemistry and physics, 71st Ed., CRC, Boca Raton, 1991

[2] A.K. Radzimska, T. Jesionowski, Zinc oxide-from synthesis to application: A review, Materials 7 (2014)2833-2881.

[3] J.K. Behera, Synthesis and characterization of nano-particles, M.Sc., Thesis, NIT, Odisa, India, 2009.

[4] A. Ohtomo, M. Kawasaki, I. Ohkubo, H. Koinuma, T. Yasuda, Y. Segawa, Structural and optical properties of $\mathrm{ZnO} / \mathrm{Mg}_{0.2} \mathrm{Zn}_{0.8} \mathrm{O}$ superlattices, Appl. Phy Lett. 75 (1999) 980-982.

[5] Eva M. Wong, Peter C. Searson, ZnO quantum particle thin films fabricated by electrophoretic deposition, Appl. Phys. Lett.77 (1999) 2939-2941.

[6] J.W. Bae, S.W. Lee, K.H. Song, J.I. Park, J.J. Park, Y.W. Ko, G.Y. Yeom, Tin oxide films deposited by ozone-assisted thermal chemical vapor deposition, Jpn. J. Appl. Phys. 38 (1999) 2917-2920.

[7] G.K. Paul, S. Bandopadhya, S.K. Sen, Transport properties of as-prepared Aldoped zinc oxide films using sol-gel method, Phys. Stat. Solid A 191(2) (2002) 509-518.

[8] B.D. Cullity, Elements of X-ray diffraction, $2^{\text {nd }}$ Edn., Addison-Wesley Publishing Company, Inc., Reading, MA, 1978.

[9] C.M. Muiva, T.S. Sathiaraj, K. Maabong, Effect of doping concentration on the properties of aluminium doped zinc oxide thin films prepared by spray pyrolysis for transparent electrode applications, Ceram. Int. 37 (2011) 555560.

[10] S.P. Ansari, F. Mohammad, Electrical studies on the composite of polyaniline with Zinc oxide nanoparticles, IUP Jour. Chem. 4 (2010) 7-18.

[11] S.P. Ansari, F. Mohammad, Studies on nanocomposites of polyaniline and zinc oxide nanoparticles with supporting matrix of polycarbonate, ISRN Mater. Sci. 2012 (2012) 129869-1-7.

[12] S.L. Patil, M.A. Chougule, S.G. Pawar, S. Sen, V.B. Patil, Effect of camphor sulfonic acid doping on structural, morphological, optical and electrical transport properties on polyaniline-ZnO nanocomposites, Soft Nanosci. Lett. 2 (2012) 46-53.

[13] S.B. Kondawar, P.T. Patil, S.P. Agrawal, Chemical Vapour sensing properties of electrospun nanofibers of polyaniline/ZnO nanocomposites, Adv. Mater. Lett. 5 (2015) 389-395. 